\title{
University Rubs Shoulders with Industry
}

from our Social Medicine Correspondent

Newcastle upon Tyne, January

TwENTY-FIVE years ago the Department of Industrial Health was set up at the University of Newcastle upon Tyne (then King's College, University of Durham) with the aid of a $£ 40,000$ grant from the Nuffield Foundation. Housed, to begin with, in the medical school and staffed by a skeleton team of twelve, the department has since grown under the guidance of Professor R. C. Browne into a large and active assembly of semiautonomous sections, inconveniently divided between the medical school and an elegant row of buildings less than a quarter of a mile away. In spite of the increasing teaching load, applied rescarch continues to receive heavy emphasis and it is refreshing to see the way in which medical and non-medical staff work harmoniously together.

In addition to university financing, now approaching $£ 50,000$ a year, the department has also received generous support from the Science and Medical Rescarch Councils, the National Coal Board, the Central Electricity Generating Board and the Nuffield Provincial Hospitals Trust among others. The largest grant so far- $£ 200,000$-has come from the Department of Health and Social Security. Made over to the department in late 1969 , the grant will make possible the setting up of a new Medical Care Research Unit, which is to be jointly directed by Professor D. J. Newell, currently head of the department's medical statistics section, and Dr John H. Walton. The general interests of the unit will be directed towards problems inherent in the unification of health services: attempts will be made to establish norms in the provision of medical care and the response to its provision; to determine the pattern and efficiency of transfer between different sources of medical care; and to investigate the relationship of preventive, medical and social care, particularly in childhood. Work currently in progress in the medical statistics section includes a statistical analysis of the causes and methods of treatment of low-back pain-

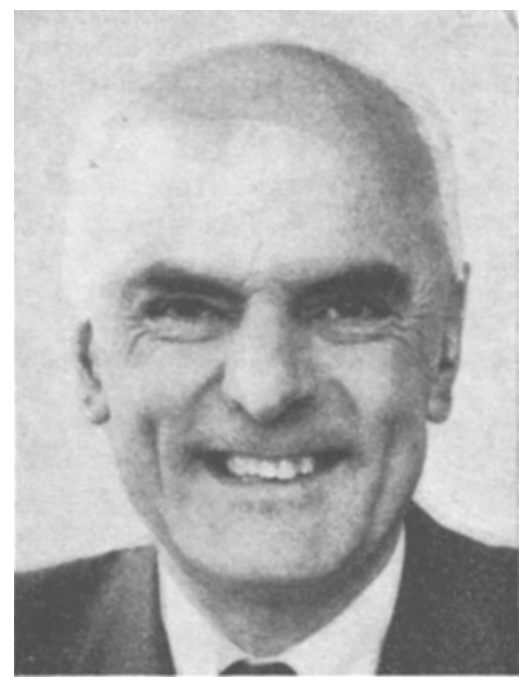

Professor R. C. Browne, an expert on coal miners' pneumoconiosis, is head of the Department of Industrial Health. part of a multi-centre trial coordinated by Professor Newell. As well as carrying out research, the section's staff provides a consulting service for the design and analysis of clinical trials and medical surveys in the medical school and teaching hospitals.

Dr J. Steel heads the active and dual functioning occupational hygiene section. On the one hand, research is carried out into the various problems linked up with health and hygiene in industry. For example, much effort is concentrated on predicting the health risk to welders and burners who are exposed to fumes containing oxides of the toxic elements copper, zinc, nickel and cobalt which result from the decomposition of surface coatings during application of intense heat. These elements can cause, among other things, metal fume fover and metal poisoning. As a result of this work, the section has acquired a national role for the pre-testing of paints and electrodes before manufacturers put the products on the market. Another current line of research is the development of a sensitive mothod for detecting lead poisoning among workers using small samples of blood. Current methods require $5-10 \mathrm{ml}$. of blood. By looking at the way in which lead is in part organically bound to blood and urine, Dr Stcel hopes to be able to predict susceptibility to lead poisoning in certain persons.

The section also tackled particular problems for local industries on a fee-for-service basis, as part of the North of England Industrial Health Service. This service, which is based in the Department of Industrial Health, has its own management committce consisting of representatives of the university, management and the Trades Union Congress and is virtually self-supporting. Although most of the work is done on a contract or consultative basis, some firms have joined as members, paying so much a head. This entitles them to advice on any matter relating to health at work and they also receive a regular visit from one of the service's medical officers. A new feature of the service is the launching this month, in Washington New Town, an industrial estate, of a group occupational health service under which an appointed nurse will make daily visits to member firms on the estate to administer first aid and to help in social and welfare matters. She will be backed up by a medical officer and may in future be joined by staff offering physiotherapy, chiropody and ophthalmic services.

Dr R. I. McCallum is currently perfecting a technique for measuring directly the amount of antimony trioxide in the lungs of process workers using an iodine radioactive jsotope and a scintillation counter. Antimony pneumoconiosis, which is more of an inconvenience than a serious clinical problem, affects workers in one factory in the north-cast, but the detection technique can be applied equally well to measuring tin in the lungs - a more common hazard. Dr McCallum is attempting to induce antimony pncumoconiosis in cats so that the amount of the element measured in living lungs can be compared with the amount present at autopsy as measured by, for example, atomic absorption spectroscopy. This will indicate the accuracy of the X-ray method. 
Two other aspects of the department's varied research programme include an investigation into the effects on the lungs of breathing in radioactive xenonheaded by Dr H. L. Leathart-and a continued ergonomic study of industrial component inspection using a conveyor belt. This study is being conducted by Mrs Judy Lion.

Also housed in the department is the Decompression Sickness Registry, directed by Dr P. D. Griffiths. Although the Medical Research Council grant supporting the registry is made to Professor D. N. Walder, in the Department of Surgery, who is concerned with the significance of gas micronuclei in the aetiology of decompression sickness (see Nature, 222, 251; 1969), the records and radiographs of thousands of men who have worked in compressed air are kept in the department. So are the new decompression tables giving the most suitable length of time for decompression, which are being widely used in compressed air work on an experimental basis. Under these tables, a man working at 44-46 pounds per square inch-almost the limit for civil engineering work-is required to decompress for 270 minutes compared with the 127 minutes required under government tables. Working in close association with other members of the MRC Decompression Sickness Panel, Dr Griffiths and Dr McCallum periodically arrange for X-rays to be taken of the limbs of men in compressed air work in the hope of detecting, at an early stage, aseptic necrosis of the bones.

\section{Growing Pains in British Universilies}

by our Education Correspondent

THE next few years could see major changes in the British system of higher education. The number of student places must double in the next ten years: that now seems to be recognized both by the government and the universities, and it is unlikely that the system will come through such expansion unchanged. But the changes will inevitably be accompanied by their fair share of arguments. Preliminary skirmishes have already been made--the Department of Education and Science, in October and December last year, discussed, with the Committee of Vice-Chancellors and with the Association of University Teachers, various ways to achieve the expansion as cheaply as possible. It seems likely, however, that both bodies will reject most of the proposals put forward, and $\mathrm{Mr}$ Gerald Fowler, Minister of State with responsibility for higher education, has already complained that academics are being hypersensitive to alleged threats to academic freedom.

The controversy has been brought to a head by the latest predictions of the demand for higher education in the 1970s. Using the Robbins basis of relating entry to higher education with numbers of school leavers, the ministry predicts that 437,000 students will be engaged in higher education in 1971-72, 557,000 in 1976-77 and 727,000 in 1981-82. It suggests, however, that colleges of education will only increase their intake by about 20,000 in the next ten years, and the universities and further education establishments will therefore bear the brunt of the expansion. Such an expansion will require about a 7 per cent annual increase in student numbers, and it is unlikely that expenditure on higher education will be allowed to grow at the same rate. Faced with the demand for places outstripping the available resources, Mr Fowler has been casting around for ways to reduce the costs per student, and it is this which has stirred up the rumblings in the universities.

Analysis of the Department of Education and Science's figures for 1959-60 to 1967-68 suggests, however, that the government may already be reducing the costs per student. Fig. I shows that expenditure on the universities rose at about the same rate as student numbers between 1959 and 1964 . But after
1965, when the Colleges of Advanced Technology were given university status, costs rose less sharply than student numbers. Even if these trends were continued, it is doubtful whether it would effect the saving which Mr Fowler wants, and moreover, expenditure on new buildings will inevitably tend to push costs up. For one thing, expansion of this order would require that several new universities must be established. It is reasonable to expect that existing institutions can do no more than treble in the next decade (only Reading and Strathclyde have done this in the past ten years), and most universities believe that about 12,000 is the maximum size that they could achieve without becoming completely impersonal establishments. Even if existing universities expand as quickly and as far as possible, the expansion would therefore fall short of the target for 1980 .

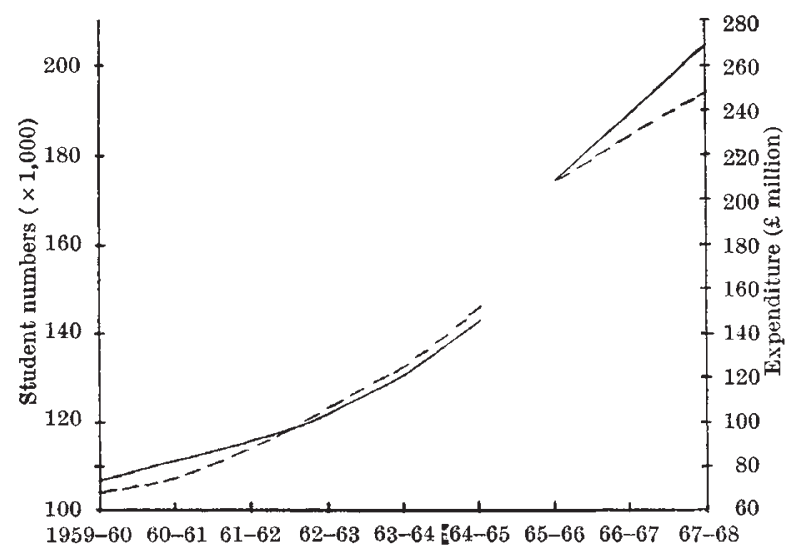

Fig. 1. Student numbers and university expenditure, 1959-68. Student numbers; ______, university expenditure.

Some change in the system therefore seems inevitable, and the Department of Education and Science has suggested thirteen proposals to the vice-chancellors and the AUT for their consideration. Individual vicechancellors will submit their own views to the ViceChancellors Committee probably early in February, and the AUT has set up a working party to formulate a 